\title{
Conclusions of the Ad-hoc Review Committee (ARC) on the International Commission on Fossil Fuels (CFF) of the International Union of Geological Sciences (IUGS) (Paris, 22nd November 2006)
}

\begin{abstract}
Background
Following the recommendations of the IUGS Strategic Planning Committee (2000) and IUGS Strategic Action Plan (2001) to appoint Ad-hoc Review Committees (ARCs) to hold reviews of all IUGSfunded scientific activities on a regular basis, the IUGS Executive Committee decided at its 56th meeting in Punta Arenas, Chile (January 6-10, 2006) that an ARC should be convened to review the IUGS International Commission on Fossil Fuels (CFF). CFF has been part of IUGS, with different names, for at least seventeen years (as Advisory Committee before 1989; as Commission from 1989 to 1999; as Task Group from 2000 to 2004, and as Commission since 2004). The last review of CFF by the IUGS Advisory Board for Research Development (ABRD) was in 1999.
\end{abstract}

Since its inception, the aim of the CFF has been to promote geoscientific research that supports the efficient exploitation of fossil fuels. This includes addressing environmental and resource management perspective, offering easy access to information on related geoscience issues and providing a forum for communication between countries and organizations within the fossil fuels field. To promote these goals the CFF has developed and deployed a geointelligence website to assist workers in obtaining important information concerning fossil fuels, especially those from developing countries and from groups outside the major industry players.

\section{ARC participants}

The ARC members appointed by the IUGS EC were: Alberto Riccardi (past IUGS Councilor, Argentina, Chair), Antonio Brambati (IUGS Treasurer, Italy), Jean-Paul Cadet (past IUGS Councilor, France), Kurt Rudolph (external expert, USA) and Carlos M. Urien (external expert, Argentina). Interviewed participants were Richard Sinding-Larsen (CFF Chair, Norway), J-M. Monget (CFF Executive Officer, France), plus Thierry Rousselin (Private Consultant for military and oil industry, Paris) invited by the CFF Chair in order to explain the main features of the Geointelligence methodology.

The meeting was held in Paris on 22 November, 2006, and was attended by all the ARC members and the CFF officers. Relevant information for the meeting included: IUGS Commission Rules, IUGS Vision and Strategic Action Plan; Terms of Reference (ToR) for ARC; CFF ToR; CFF Annual Reports for 2000-2005; the Report of the last CFF Review, 1999. Additional documentation was requested (i) from R. Sinding-Larsen, on the development of CFF since its start, on its main accomplishments of the last years and on its planned activities; and (ii) from J-M. Monget, on the Geointelligence effort, with regard to its principles and methodology, its application by CFF and by other interested parties, and its bearing in the IUGS Strategic Plan. In response, R. Sinding-Larsen distributed, at the beginning of the meeting, a copy of the CFF "Annual Report 2006 to the International Union of Geological Sciences", and J-M. Monget sent, one week before the meeting, a copy of a paper by Gardner, J.V., Monget, J-M., Sinding-Larsen, R., and Warner, T., entitled "Geointelligence for Assessing Natural Resource Project Risks".
During the ARC meeting, the CFF officers were interviewed. Main areas for discussion were: historical overview, major accomplishments and problems, financial overview on income and expenditures, and planned activities of CFF.

\section{Meeting highlights}

During the meeting Sinding-Larsen gave a presentation on a number of items: (i) change in focus of CFF through time; (ii) significance of CFF on the problem of Energy and Environment; and (iii) Bayesian Discovery Process Modeling technique as applied in Doba oil field (Chad); Thierry Rousselin gave an account of the New Geospatial Intelligence and on Geointelligence; and J-M. Monget made some comments on the paper by Gardner, J.V., Monget, J-M., Sinding-Larsen, R., and Warner, T., entitled "Geointelligence for Assessing Natural Resource Project Risks". The above mentioned documents and these presentations resulted in a number of comments, questions and additional explanations. Important items mentioned were:

- that CFF focus is on National Governments and their increased interest in transparency, especially in regard to realistic estimates of oil resources.

- that CFF serves IUGS as a vehicle to develop relationships among Industry, Academic Institutions, and Governments.

- that CFF helps industry, using geological knowledge, to prevent misinformation about oil exploration disseminated by groups without proper expertise (e.g. NGO's).

- that CFF serves IUGS to improve knowledge, on marginal areas with oil resources, and on the existence of unconventional hydrocarbon resources, averting ideas held by the public on peak oil.

- that CFF, not being an oil company with its own data, applies a Bayesian Discovery Process Modeling technique to published data in order to assess oil resource project risks and volumes (e.g. in the Doba oil fields, Chad).

- that the New Geospatial Intelligence is based on a new combination of OSINT (Open Source INTelligence, cross-checked public information available on the web) + Virtual Globes (imaginary available on the web) + Web 2.0 practices.

- that Geointelligence on the web gives efficient and inexpensive results and facilitates the use of web data to any person. It is based on: a) Wiki interpreting all shared knowledge; b) virtual globe; c) elearning techniques; d) web conference tools.

- that the Geointelligence methodology was applied by the CFF officers, first in 1998 to Uranium, and afterwards to a resource considered of higher importance, i.e. oil, although it is also being used in Hydropower projects. Although it is recognized that this technique would be more useful if integrated with land use planning, environmental evaluations, water resources, etc.

- that CFF was a pioneer in using this methodology, but there is no registered copyright on it, and that the term "Geointelligence" has now become well known and is used by many persons. 
- that Geointelligence can not be equated to Geoknowledge, an entry word that is also present in the web, as Geoknowledge refers only to interpretations and not to data gathering.

- that although it is realized that much public domain data on oil resources are distributed to impress investors, and therefore any analysis of these data would produce erroneous results, the final $\mathrm{CFF}$ aim is to induce countries to produce free information that could be used by all neighbor countries. In that way, the potential for conflict is reduced.

- that once results are published, they will be integrated with other IUGS bodies. In order to promote a region, and taking into account $\mathrm{N}-\mathrm{S}$ and W-E world differences with regard to data availability, IUGS is considered a facilitator, whilst CFF study products go to IUGS bodies for dissemination.

- that Central Africa was selected as a target region because it looked like a good prospect, especially considering that the World Bank was interested, and because there is not any other organization to do that job.

- that CFF is trying to contact African pressure groups to explain the current importance of transparent resource assessments, in contrast to past activities that are viewed as exploitive.

- that it is recognized that the issue is a political one, that consensus is easier to reach in the North Sea than in Africa, and that oil companies publish dated information, and have more information than is available to the public, but that the goal of oil companies is only commercial, whilst IUGS is looking for ways to increase cooperation.

- that it is acknowledged that National companies in African countries have access to a lot of proprietary information that is much superior to public domain data, and therefore, that there is no advantage of such countries using public domain information, but the idea is that information could be used for interchange with other countries.

- that Central Africa appears to be a target of convenience, and is too localized, and even if a more global approach would have more impact, it is impractical to address a larger scale as CFF is in a testing/evaluation phase.

- that it is acknowledged that in spite of the fact that CFF seems to be a team working on behalf of some countries, and consequently it is a testing and evaluation project to be expanded to other parts of the world, for the next year is still restricted to the same region.

- that CFF tried to initiate activities in Bolivia, but a key contact person in Government was removed from his position, and CFF decided to engage in other parts of Africa (Zambia, Angola).

- that in order to achieve its goals, CFF should be disseminating information throughout the world using its relationships with other organizations and through a variety of publications.

- that CFF officers have talked with people from three different countries and they have discussed the use of Geointelligence with the World Bank and the US Geological Survey, which are interested in an independent type of evaluation. CFF officers were also ready to collaborate with other IUGS bodies, but they were not able to do this on a widespread basis yet; and that thus far CFF have restricted their publications to technical matters.

- that CFF expenditures include USD 3500 provided by IUGS, for the last year of financial support, which are used as seed money in African countries. Other money comes from the Norwegian University of Science and Technology, besides 30,000 E which are provided by Norway.

\section{ARC Conclusions}

Following a discussion of the items summarized above, the ARC arrived at several conclusions and a final recommendation.

1) Several goals described by the CFF, are quite important, i.e. (i) study geological problems of fundamental and applied character related to the fossil fuels; (ii) facilitate investigation of problems related to fossil fuels which require interdisciplinary and international cooperation between academic and industrial researchers; (iii) study how regional and national resource management practices can be devised in order to neutralize triggers for conflict. However, CFF, appears to be more political than scientific, and concrete results on the listed goals are not clear, despite more than 15 years of work.

2) The CFF Geointelligence proposal has potential for many activities sponsored by IUGS. But on the specific field of Fossil Fuels, CFF analyses are built upon historical and very limited data as they are released by the oil industry. However, recent data (not open to the public) probably play a significant role in determining political outcomes.

Concerning the general performance of the CFF, the Review Committee has noticed that:

1) CFF has not been able to integrate its activities neither with other energy fields, as recommended by the 1999 ABRD review, nor with other geological issues.

2) Aside from the CFF Officers it is not clear that other CFF members listed in the Annual Reports have been actively or effectively participating in CFF activities.

3) CFF has not been able (as planned), to develop working relationships with other IUGS bodies and other geological and non-geological organizations, and/or initiate an IGCP project. Additionally, it has not been able to expand to other world regions beyond central Africa.

4) CFF dissemination of results is almost non existent, and is mainly focused on high level descriptions of a general methodology.

\section{Final recommendation}

Based on the Conclusions outlined above, the ARC final recommendation is to terminate CFF activities, and to thank CFF officers and members for the work done to develop the Geointelligence methodology, to improve international cooperation, and to help IUGS to further its goals. 